\title{
PENGHITUNG SETPOINT DOWN COUNTER OTOMATIS PADA LAMPU LALU LINTAS DENGAN MENGGUNAKAN PANEL LED DOT MATRIX
}

\author{
Galih Mustiko Aji ${ }^{1}$, Purwiyanto ${ }^{2}$ \\ ${ }_{1,2}$ Jurusan Teknik Elektronika Politeknik Negeri Cilacap \\ E-mail: galihma@gmail.com,purwi_1979@yahoo.com
}

\begin{abstract}
Down coun ter on the traffic light provides information for drivers on how long the lamps will be on or off, then they are not careless who can cause traffic jam and accidents. The instalation of down counter needs value of set point which derived from the traffic light controller or it is set manually by technician. The design of down coun ter which is capable of standing by itself, it is possible to use less cables and it will facilitate on its time changing and the main tenance of traffict light. In this research, a down coun ter which counts by itself will be create value of set point which design ed by using display of let dot matrix panel with the size of $32 x 32$ pixel. It is able to display figures as many as 2 digits of 99 until 00.
\end{abstract}

Keywords: atmega 32, dot matrix panel, down counter, traffict light

\section{INT ISARI}

Down counter pada lampu lalu lintas memberikan informasi kepada pengendara tentang lama waktu nyala atau mati lampu, sehingga pengendara tidak lengah yang dapat menyebabkan kemacetan dan kecelakaan. Instalasi down counter membutuhkan nilai setpoint yang berasal dari kontroler lampu lalu lintas atau diset secara manual oleh teknisi. Desain downcounter yang mampu berdiri sendiri memungkinkan penggunaan kabel yang lebih sedikit dan kemudahan pada saat perubahan waktu dan perawatan lampu lalu lintas. Dalam penelitian ini sebuah downcounter yang mampu menghitung sendiri nilai setpoint dirancang dengan menggunakan penampil panel led dot matrix berukuran $32 \times 32$ pixel. Down counter mampu menampilkan angka sebanyak 2 digit dari 99 sampai dengan 00.

Kata Kunci : atmega32, down counter, lampu lalu lintas, panel dot matrix

\section{PENDAHULUAN}

Teknologi pengendalian lampu lalu lintas mengggunakan dua metode yaitu teknologi jaringan yang memanfaatkan kabel dan teknologi standalone [1]. Penggunaan kabel sebagai media jaringan sangat rumit dan memiliki tingkat kesulitan cukup tinggi dalam perawatan. Penambahan fitur seperti suara peringatan atau downcounter akan memaksa penggunaan kabel lebih banyak.

Down counter pada lampu lalu lintas bermanfaat bagi pengendara untuk dapat mengetahui kapan suatu lampu itu akan hidup atau mati, sehingga pengendara tidak lengah yang dapat menyebabkan kemacetan dan kecelakaan [2]. Down counter membutuhkan nilai setpoint sebagai nilai awal penghitungan mundur pada masing-masing lampu. Nilai setpoint adalah lamanya waktu menyala pada masing-masing lampu merah, kuning dan hijau. Nilai setpoint dapat ditentukan oleh teknisi secara manual atau terintegrasi dengan kontroler lampu lalu lintas.

Penggunaan sistem down counter yang terintegrasi ke kontroler lampu lalu lintas memaksa penggunaan seluruh pin mikrokontroler dan kabel yang digunakan sangat banyak [3]. Penentuan setpoint secara manual akan sangat merepotkan pada saat instalasi ataup un pada saat p enjadwalan ulang lampu lalu lintas.

Berdasarkan kondisi di atas maka dalam penelitian ini dirancang sebuah down counter yang dipasang standalone yang mampu menghitung nilai setpoint secara otomatis dengan menggunakan penampil panel led dot matrix. 


\section{A. Tujuan}

1. Merancang down counter 2 digit dengan menggunakan display panel led dot matrix.

2. Merancang down counter untuk lalu lintas yang terpasang standalone yang dapat menentukan nilai setpoint secara otomatis.

\section{B. Identifikasi Masalah}

Pemasangan down counter banyak mengalami kendala terutama pengkabelan dan pengaturan setpoint. Penggunaan kabel yang banyak akan sangat rumit pada saat perawatan. Pengaturan setpoint down counter secara manual akan memaksa pengaturan ulang pada saat pengaturan ulang lampu lalu lintas. Otomatisasi penghitungan setpoint down counter memungkinkan down counter menyesuaikan sendiri nilai setpoint sesuai lama waktu nyala lampu lalu lintas dan mengurangi jumlah pengkabelan.

\section{METODE PENELITIAN}

Tahapan penelitian dalam otomatisasi penghitung setpoint down counter pada lampu lalu lintas dengan menggunakan panel dot matrix meliputi:

\section{A. Perancangan Sistem}

Diagram blok sistem penghitung setpoint down counter otomatis pada lampu lalu lintas dengan menggunakan panel led dot matrix secara keseluruhan diperlihatkan pada Gambar 1.

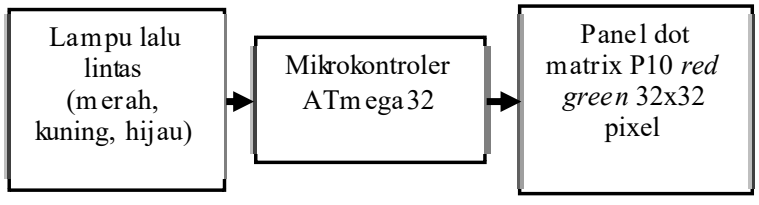

Gambar 1. Blok diagram sistem down counter

Masukan sistem berasal dari kondisi nyala lampu lalu lintas yaitu lampu merah, kuning dan hijau. Mikrokontroler akan mengindera dan menghitung lama waktu nyala lampu untuk tiaptiap lampu hijau, kuning dan merah dalam satu siklus. Hasil penghitungan pada satu siklus tersebut akan disimpan oleh mikrokontroler sebagai nilai setpoint down counter yang akan ditampilkan pada panel led dot matrix. Secara detail sistem pencacahan yang dilakukan dapat digambarkan dalam diagram alir pada Gambar 2.

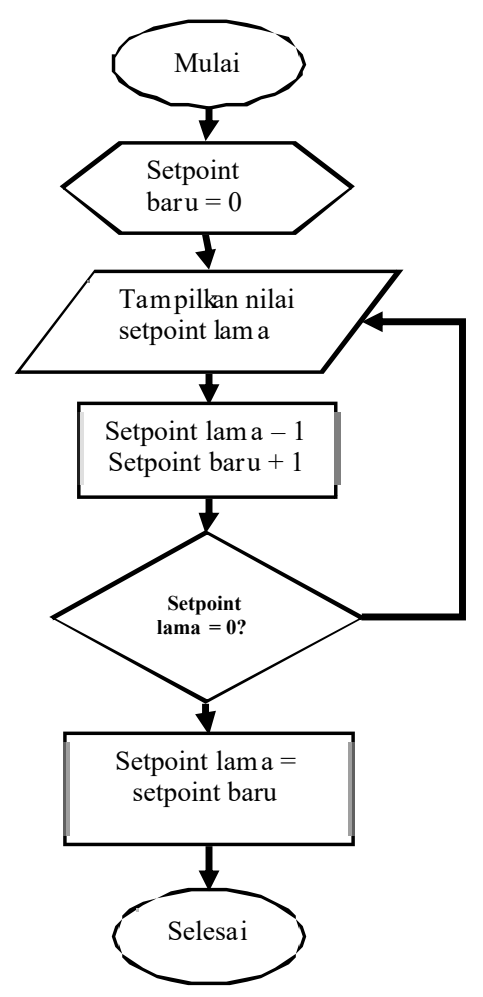

Gambar 2. Diagram alir sistem down counter

Down counter akan menampilkan 2-digit angka pada panel led dot matrix dengan menggunakan setpoint yang didapat dari satu siklus lampu lalu lintas sebelumnya. Pada saat down counter mencacah mundur, mikrokontroler akan menghitung naik setiap detik pencacahan y ang disimpan sebagai setpoint baru selama satu siklus sampai dengan nilai setpoint lama bernilai 0 . Setelah itu nilai setpoint lama akan diganti dengan nilai penghitungan naik yang dilakukan oleh mikrokontroler.

\section{B. Masukan Sistem dan Catu Daya \\ Untuk mendapatkan nilai setpoint maka} Gnd masing-masing lampu dihubungkan ke pinpin mikrokontroler ATmega32 sebagai digital input active low. Sebagai pengaman rangkaian digunakan optocoupler untuk men-switch level tegangan rangkaian. Catu daya down counter mengambil dari instalasi kabel lampu lalu lintas, karena jumlah kabel yang terbatas dan tidak ditemukan jalur tersendiri untuk kutub negatif (Gnd) maka digunakan dioda 1N4002 sebagai penyearah serta sumber Gnd agar masingmasing lampu tidak terganggu. Secara keseluruhan saluran catu daya dan saluran input sistem down counter dapat digambarkan seperti pada Gambar 3. 


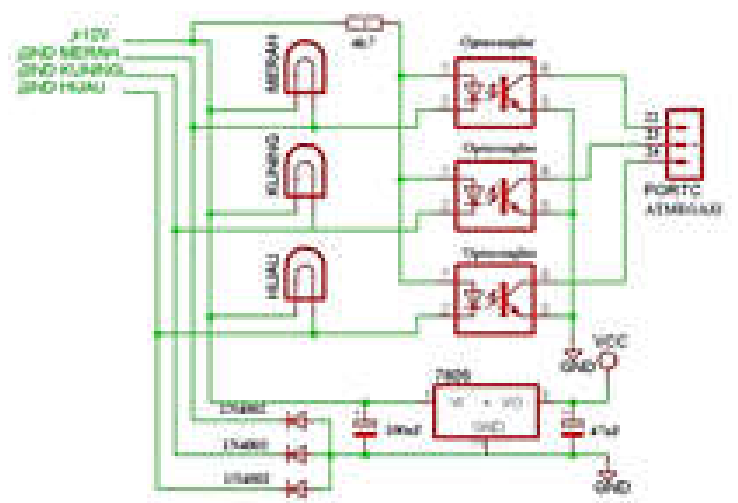

Gambar 3. Saluran input dan saluran catu daya

Pada Gambar 3 menunjukkan ketika lampu meny ala maka logika pada input mikrokontroler adalah ' 0 ' (LOW), dan ketika lampu mati maka logika pada input mikrokontroler adalah ' 1 ' (HIGH).

\section{Pembentukan Karakter pada Panel LED Dot Matrix}

Bentuk karakter dibuat menggunakan bantuan perangkat lunak Microsoft Excel 2007 tujuannya adalah agar mudah menghitung nilai binary memorinya. Karakter yang berwarna merah menunjukkan memori harus berlogika "1" dan yang berwarna putih menunjukkan memori berlogika " 0 ". Urutan penulisan dari pengalamatan LED dijelaskan padaGambar 4.

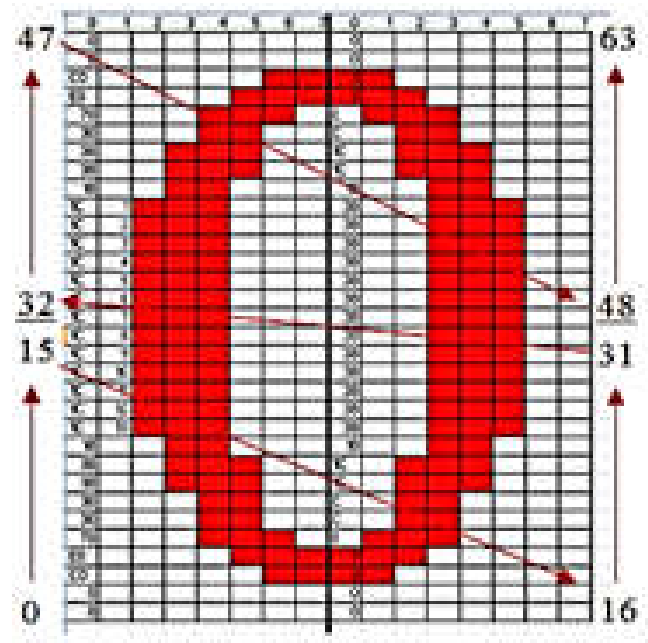

Gambar 4. Urutan pembuat an array karakter angka

Display dot matrix digunakan untuk menampilkan karakter yang berupa angka dari 0 sampai dengan 9. Display dot matrix yang digunakan keseluruhan memiliki ukuran $32 \times 32$ pixel. Ukuran dot matrix tersebut digunakan untuk menampilkan dua digit angka, sehingga masing-masing digit akan memiliki ukuran $16 \times 32$ pixel. Karakter-karakter yang akan dimunculkan harus didesain dan disimpan dalam memori mikrokontroler, berdasarkan teori tentang memori mikrokontroler AVR maka untuk satu karakter angka akan membutuhkan sebesar 64 byte memori. Sehingga total memori yang dibutuhkan untuk seluruh karakter dari 0 sampai dengan 9 adalah 640 byte.

Posisi LED dot-matrix terdiri dari dua buah panel dot-matrix yang disusun atas (B) dan bawah (A), sehingga untuk menampilkan karakter angka pada Dot-matrix akan dibagi menjadi dua posisi seperti pada Gambar 5.

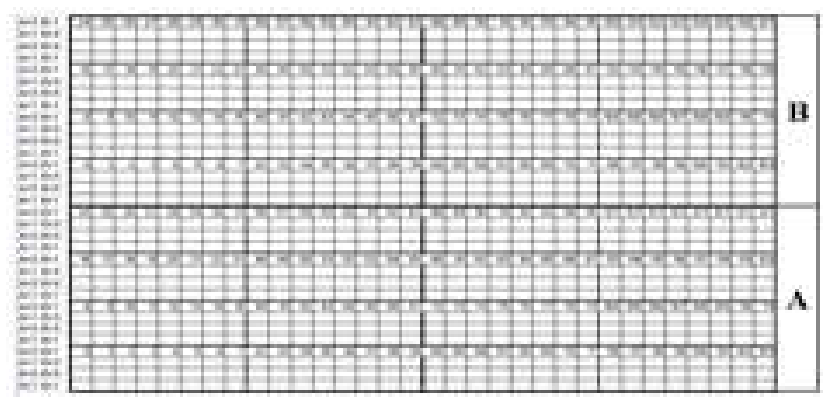

Gambar 5. Alamat register dot matrix

Setiap LED pada panel dot matrix memiliki satu alamat bit mulai dari 0 sampai dengan 127 . Setiap baris tersusun atas 4 larik kombinasi register A dan B. Untuk daftar register baris dapat dilihat pada Tabel 1 .

T abel 1. Register untuk menentukan baris

\begin{tabular}{|c|l|l|}
\hline \multicolumn{1}{|c|}{$A$} & \multicolumn{1}{|c|}{ B } & \multicolumn{1}{c|}{ Baris } \\
\hline$A=1$ & $B=1$ & Baris 1 \\
\hline$A=0$ & $B=0$ & Baris 2 \\
\hline$A=1$ & $B=0$ & Baris 3 \\
\hline$A=0$ & $B=1$ & Baris 4 \\
\hline
\end{tabular}

Pada penelitian ini digunakan 2 (dua) buah panel dot matrix sehingga ukuran total panel dot matrix adalah $32 \times 32$ pixel, dengan konfigurasi seperti pada Gambar 6.

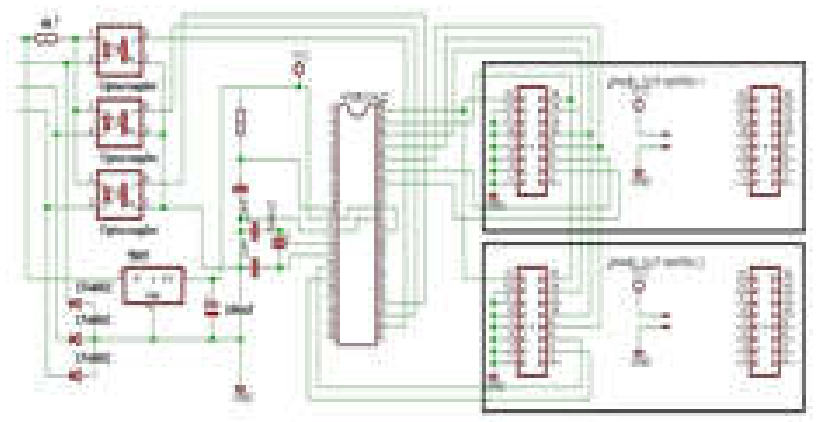

Gambar 6. Rangkaian kendali panel dot matrix 
Kedua buah panel dot matrix di atas dikonfigurasi paralel yang terhubung langsung ke mikrokontroler ATmega32. Adapun konfigurasi konektor input panel dot matrix dapat dilihat pada Tabel 2 .

Tabel 2. Koneksi mikrokontroler dengan panel dot matrix

\begin{tabular}{|c|c|c|c|c|c|c|}
\hline \multirow[b]{2}{*}{ No } & \multicolumn{3}{|c|}{ Led Dot Matrix } & \multicolumn{2}{|c|}{ ATmega32 } & \multirow[b]{2}{*}{ Deskripsi } \\
\hline & $\begin{array}{l}\text { No. } \\
\text { Pin }\end{array}$ & P1 & P2 & $\begin{array}{l}\text { No. } \\
\text { Pin }\end{array}$ & Nama Pin & \\
\hline 1 & 16 & A & & 39 & PORTA.1 & $\begin{array}{l}\text { Input register } \\
\text { untuk menga tur } \\
\text { baris }\end{array}$ \\
\hline 2 & 14 & B & & 38 & PORTA. 2 & $\begin{array}{l}\text { Input register } \\
\text { untuk menga tur } \\
\text { bar is }\end{array}$ \\
\hline 3 & 8 & STR & & 36 & PORTA.4 & $\begin{array}{l}\text { Menahan da ta } \\
\text { y ang suda h } \\
\text { dikirim }\end{array}$ \\
\hline 4 & 6 & DR & & 35 & PORTA. 5 & $\begin{array}{l}\text { Data led warna } \\
\text { merah }\end{array}$ \\
\hline 5 & 4 & DG & & 34 & PORTA. 6 & $\begin{array}{l}\text { Data led warna } \\
\text { hijau }\end{array}$ \\
\hline 6 & 15 & $\mathrm{OE}$ & & 40 & PORTA.0 & $\begin{array}{l}\text { Meny alakan } \\
\text { led }\end{array}$ \\
\hline 7 & 10 & Clk & & 37 & PORTA.3 & $\begin{array}{l}\text { Untuk } \\
\text { mengirim data } \\
\text { clock }\end{array}$ \\
\hline 8 & 16 & & A & 39 & PORTA.1 & $\begin{array}{l}\text { Input register } \\
\text { untuk menga tur } \\
\text { baris }\end{array}$ \\
\hline 9 & 14 & & B & 38 & PORTA. 2 & $\begin{array}{l}\text { Input register } \\
\text { untuk m enga tur } \\
\text { bar is }\end{array}$ \\
\hline 10 & 8 & & STR & 36 & PORTA.4 & $\begin{array}{l}\text { Menahan da ta } \\
\text { y ang sudah } \\
\text { dikirim }\end{array}$ \\
\hline 11 & 6 & & DR & 14 & PORTD.0 & $\begin{array}{l}\text { Data led warna } \\
\text { merah }\end{array}$ \\
\hline 12 & 4 & & DG & 15 & PORTD.1 & $\begin{array}{l}\text { Data led warna } \\
\text { hijau }\end{array}$ \\
\hline 13 & 15 & & $\mathrm{OE}$ & 40 & PORTA.0 & $\begin{array}{l}\text { Meny ala kan } \\
\text { led }\end{array}$ \\
\hline 14 & 10 & & Clk & 37 & PORTA.3 & $\begin{array}{l}\text { Untuk } \\
\text { mengirim data } \\
\text { clock }\end{array}$ \\
\hline
\end{tabular}

\section{PENGUJIAN DAN ANALISA}

\section{A. Pengujian Konsumsi Daya}

Pada pengujian ini dilakukan pengukuran terhadap arus (I) dan tegangan (V) untuk mengetahui konsumsi daya yang dibutuhkan pada masing-masing proses kerja pada down counter ketika posisi panel dot matrix menyala pada warna merah dan hijau. Besarnya daya didapatkan dengan menggunakan perhitungan manual dengan mengalikan nilai tegangan dengan arus berdasarkan persamaan berikut.

$$
P=V x I
$$

dimana,

$$
\begin{array}{lll}
\mathrm{P} & = & \text { Daya(Volt Ampere) } \\
\mathrm{V} & = & \text { Tegangan (Volt) } \\
\mathrm{I} & = & \text { Arus (Ampere) }
\end{array}
$$

Pengukuran dilakukan untuk masingmasing karakter angka dari ' 0 ' sampai ' 9 ' untuk digit satuan, dan untuk digit puluhan dibiarkan pada karakter angka ' 0 '. Hasil pengukuran daya dapat dilihat pada Tabel 3 dan Tabel 4.

Tabel 3. Pengukuran Daya Dot-matrix Warna Merah

\begin{tabular}{|c|c|c|c|c|c|}
\hline \multirow{2}{*}{ No } & \multicolumn{2}{|c|}{$\begin{array}{c}\text { Tampilan Angka } \\
\text { Dot-matrix }\end{array}$} & $\begin{array}{c}\text { Tegangan } \\
\text { (Volt) }\end{array}$ & $\begin{array}{c}\text { Arus } \\
\text { (Ampere) }\end{array}$ & $\begin{array}{c}\text { Daya } \\
\text { ( VA ) }\end{array}$ \\
\cline { 2 - 4 } & Puluhan & Satuan & & & \\
\hline 1 & $' 0 '$ & $' 0 '$ & 12,2 & 1,70 & 20,74 \\
\hline 2 & $' 0 '$ & $' 1 '$ & 12,2 & 1,60 & 19,52 \\
\hline 3 & $' 0 '$ & $' 2 '$ & 12,1 & 1,61 & 19,48 \\
\hline 4 & $' 0 '$ & $' 3 '$ & 12,0 & 1,65 & 19,80 \\
\hline 5 & $' 0 '$ & $' 4 '$ & 11,9 & 1,68 & 19,99 \\
\hline 6 & $' 0 '$ & $' 5 '$ & 12,0 & 1,70 & 20,40 \\
\hline 7 & $' 0 '$ & $' 6 '$ & 12,1 & 1,70 & 20,57 \\
\hline 8 & $' 0 '$ & $' 7 '$ & 12,0 & 1,65 & 19,80 \\
\hline 9 & $' 0 '$ & $' 8 '$ & 12,0 & 1,75 & 21,00 \\
\hline 10 & $' 0 '$ & $' 9 '$ & 12,0 & 1,70 & 20,40 \\
\hline \multicolumn{7}{|l|}{ Daya rata-rata } & & & $\mathbf{2 0 , 1 7}$ \\
\hline
\end{tabular}

Tabel 4. Pengukuran Daya Dot-matrix Warna Hijau

\begin{tabular}{|c|c|c|c|c|c|}
\hline \multirow{2}{*}{$\begin{array}{c}\mathrm{N} \\
\mathrm{o}\end{array}$} & $\begin{array}{c}\text { Tampilan Angka } \\
\text { Dot-matrix }\end{array}$ & \multirow{2}{\text{Tegangan}}{$\begin{array}{c}\text { Arus } \\
\text { (Volt) }\end{array}$} & $\begin{array}{c}\text { Daya } \\
\text { (Ampere) }\end{array}$ & \\
\cline { 2 - 3 } & Puluhan & Satuan & & & \\
\hline 1 & $' 0 '$ & $' 0 '$ & 12,0 & 1,75 & 21,00 \\
\hline 2 & $' 0 '$ & $' 1 '$ & 12,1 & 1,73 & 20,93 \\
\hline 3 & $' 0 '$ & $' 2 '$ & 12,1 & 1,74 & 21,05 \\
\hline 4 & $' 0 '$ & $' 3 '$ & 12,0 & 1,76 & 21,12 \\
\hline 5 & $' 0 '$ & $' 4 '$ & 12,0 & 1,79 & 21,48 \\
\hline 6 & $' 0 '$ & $' 5 '$ & 12,0 & 1,77 & 21,24 \\
\hline 7 & $' 0 '$ & $' 6 '$ & 12,0 & 1,75 & 21,00 \\
\hline 8 & $' 0 '$ & $' 7 '$ & 12,1 & 1,72 & 20,81 \\
\hline 9 & $' 0 '$ & $' 8 '$ & 12,1 & 1,83 & 22,14 \\
\hline 10 & $' 0 '$ & $' 9 '$ & 12,0 & 1,75 & 21,00 \\
\hline \multicolumn{7}{|c|}{ Daya rata-rata } & & & $\mathbf{2 1 , 1 7}$ \\
\hline
\end{tabular}

Dari Tabel 3 dan Tabel 4 dapat diketahui bahwa arus y ang dibutuhkan untuk meny alakan LED padawarna hijau lebih besar dibandingkan warna merah dengan daya rata-rata warna merah adalah 20,17 VA dan daya rata-rata warna hijau adalah 21,17 VA.

\section{B. Pengujian Bentuk Karakter Angka}

Pada pengujian ini akan menampilkan untuk angka pada panel dot-matrix y ang menggunakan mikrokonntroler ATmega32. Berikut ini adalah 
hasil pengujian tampilan angka pada LED Dotmatrix.
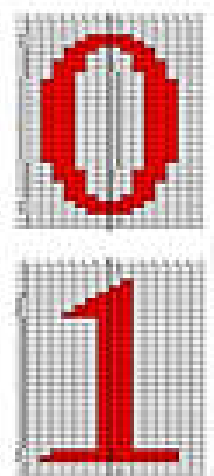
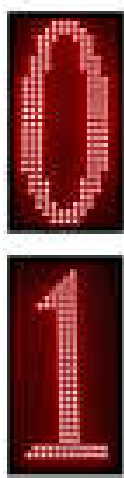
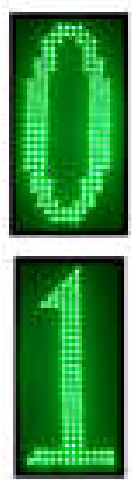

Gambar 7. Desain karakter dan hasilnya dalam warn a merah dan hijau

Dari Gambar 7 menunjukan bahwa pada panel dot-matix dapat menampilkan angka yang sesuai dengan bentuk yang sudah direncanakan dalam perancangan bentuk karakter yang telah dibuat dan diproses oleh mikrokontroler ATmega32, meliputi tampilan warna led hijau maupun led berwarna merah secara bergantian yang sesuai instruksi perintah pada program mikrokontroler.

\section{Pengujian Counter Down 2 Digit}

Dalam pengujian ini akan menunjukan proses counter down 2 digit untuk mengetahui kesesuaian perubahan angka pada panel dot matrix yang dilihat di setiap satu detiknya. Proses count down 2 digit dapat dilihat pada Gambar 8.

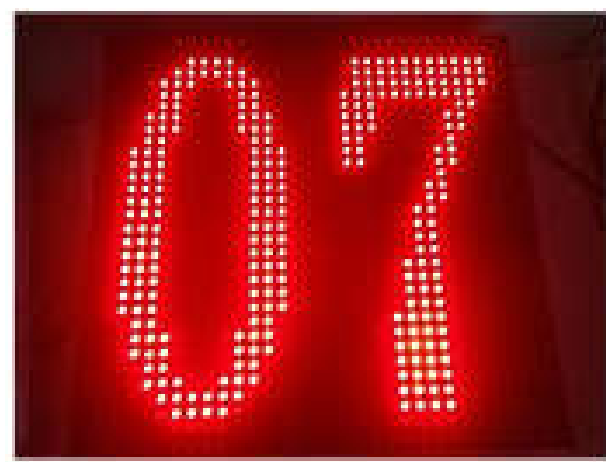

Gambar 8. Tampilan karakter 2 digit down counter

Pada Gambar 8 menunjukan bahwa proses counter down sebanyak 2 digit telah berhasil, sesuai dengan perubahan waktu dalam detik y ang dilihat dengan perubahan setiap detik.

D. Pengujian Rekaman Setpoint Down Counter

Pengujian rekaman setpoint dimaksudkan untuk mengetahui simpangan yang terjadi antara nilai lama lampu yang diberikan dengan nilai yang terekam dan ditampilkan pada awal down counter berjalan.

Pengujian dilakukan dengan memberikan nilai lama waktu menyala lampu merah, kuning dan hijau pada kontroler lampu lalu lintas. Tampilan lamanya waktu ditampilkan pada $L C D$ Character $16 \times 2$ seperti yang ditunjukkan pada Gambar 9.

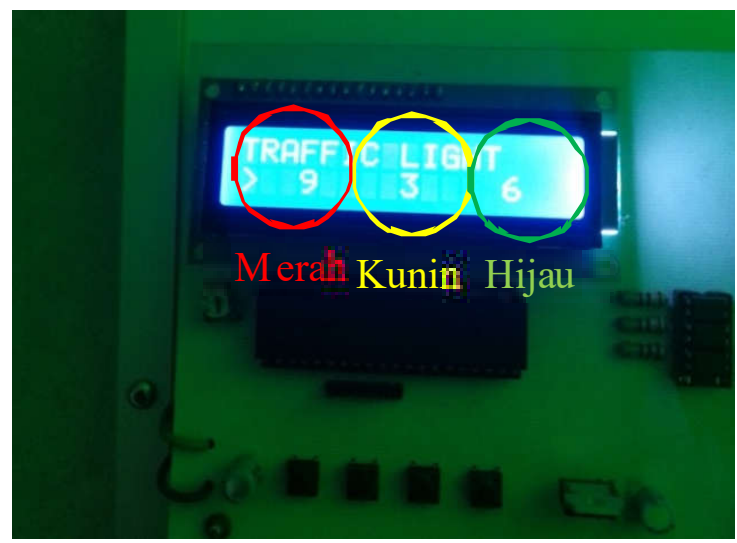

Gambar 9. Pengaturan waktu pada kontroler lampu lalu lint as

Dari Gambar 9 dari kiri ke kanan secara urut menunjukkan lamanya waktu menyala merah adalah 9 detik, kuning adalah 3 detik dan hijau adalah 6 detik. Nilai yang diatur melalui miniatur lalu lintas ini kemudian akan direkam oleh count down dan hasilnya ditampilkan dalam panel dot matrix seperti yang ditunjukkan pada Gambar 10 .

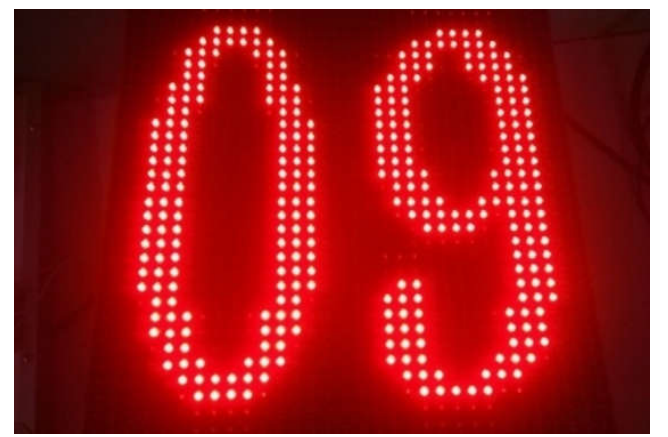

Gambar 10. Proses down counter posisi lampu merah

Gambar 10 menunjukkan hasil perekaman y ang dilakukan oleh down counter untuk lama waktu menyala lampu warna merah. Angka 9 menunjukkan bahwa lampu lalu lintas berwarna merah lamanya adalah 9 detik, sesuai dengan pengaturan pada LCD Character 16x2. Sedangkan untuk warna hijau menunjukkan angka 6 yang artinya bahwa lampu lalu lintas 
berwarna hijau lamanya 6 detik seperti yang ditunjukkan pada Gambar 11.

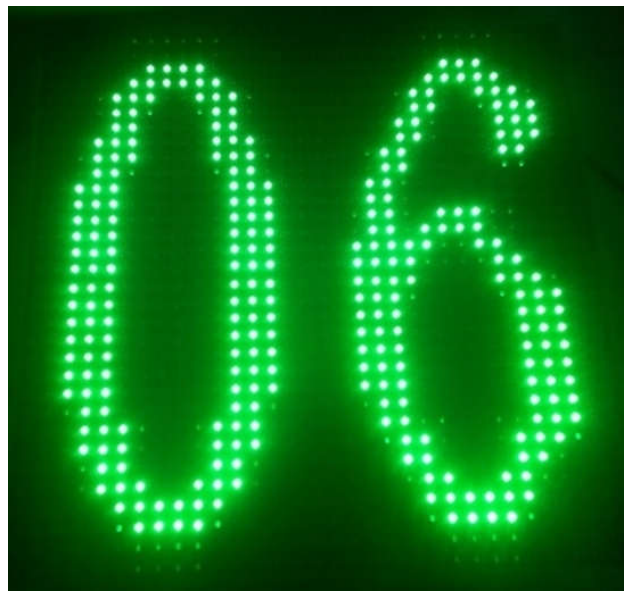

Gambar 11. Proses down counter posisi lampu hijau

Pada Gambar 11 menunjukan pengujian untuk menampilkan waktu pada saat lampu berwarna hijau sesuai dengan pengaturan pada lampu lalu lintas, untuk setting waktu lampu hijau 6 detik.

\section{KESIMPULAN}

Kesimpulan yang dapat ditarik dalam penelitian ini adalah sebagai berikut:

1. Daya yang digunakan untuk menyalakan LED Dot-matrik untuk warna hijau lebih besar dibandingkan warna merah. Dengan daya rata-rata warna merah adalah 20,17 VA dan daya rata-rata warna hijau adalah 21,17 VA.

2. Down counter mampu menunjukkan 2 digit angka dengan nilai maksimum adalah 99 dan minimum adalah 00 .

3. Down counter mampu menunjukkan hitungan mundur melalui rangkaian dot matrix yang sesuai dengan durasi lamanya nyala masing-masing lampu lalu lintas.

\section{DAFTAR PUS TAKA}

[1] Ta'ali dan Hastuti. 2014. Komputerisasi Pengaturan Lampu Lalu Lintas. Jurnal Teknologi Informasi dan Pendidikan. Vol. 7 No. $2: 122-137$.

[2] Suryadi. 2009. Pengatur Lampu Lalu Lintas Sistem Digital Berbasiskan Mikrocontroler. Elektron Vol.1 No.1 : 60 - 66.
[3] Alfith. 2015. Perancangan Traffic Light Berbasis Microcontroller ATmegal6. Jurnal Momentum. Vol. 17 No. $1: 1$ - 7.

[4] Datasheet Microcontroller ATmega32. Diunduh dari

http://www.atmel.com/images/doc2503.pdf pada 26 januari 2017.

[5] Julisha, Benny. 2013. Perancangan display LED Dot-Matrix menggunakan Mikrokontroler Atmega32. Pontianak : Jurusan Teknik Elektro Fakultas Teknik Universitas Tanjungpura Pontianak.

[6] Saefullah, Asep.2008. Perancangan Sistem Timer pada Lampu Lalu Lintas dengan Mikrokontroler AVR. STMIK Raharja.

[7] Friedolin, Hasian. 2010. Perancangan Switching Power Supply Mencatu Sistem Pensaklaran IGBT pada Inverter. Teknik Elektronika, Universitas Indonesia.

[8] Prabowo, Listyo Ari. 2003. Down Counter 4 Pilihan Berbasis Mikrokontroler AT89C2051. Universitas Gunadarma. 